\title{
Contrasting behavioural responses of grazing mayflies and detritivorous caddisflies to predatory fish
}

\author{
Luz Boyero $^{A, B, D}$, Pedro A. Rincón ${ }^{C}$ and Jaime Bosch ${ }^{C}$ \\ AWetland Ecology Department, Doñana Biological Station - CSIC, Avda. Americo Vespucio s/n, \\ 41092 Sevilla, Spain. \\ ${ }^{B}$ School of Marine and Tropical Biology, James Cook University, Townsville, Qld 4811, Australia. \\ ${ }^{\mathrm{C}}$ Museo Nacional de Ciencias Naturales - CSIC, José Gutiérrez Abascal 2, 28006 Madrid, Spain. \\ ${ }^{D}$ Corresponding author. Email: luz.boyero@ebd.csic.es
}

\begin{abstract}
Invertebrates living in streams where predatory fish are present are often able to detect them through waterborne chemical cues and respond with behavioural changes that lower predation risk. We hypothesised that behavioural responses to a predatory fish (brown trout, Salmo trutta) would be stronger in grazing mayflies (Baetis sp. and Epeorus sp.) than in detritivorous caddisflies (Potamophylax latipennis and Chaetopteryx sp.) in a montane stream in central Spain, because of differences in their foraging ecology and the presence of a protective case in the latter. Grazing mayflies reduced their rates of movement and entrance into the drift when trout were present, but this response disappeared shortly after trout removal by electrofishing. Mayflies also showed marked drift diel periodicity when trout were present. In contrast, detritivorous caddisflies responded to the potential predation threat by withdrawing into their case. However, their response was the same regardless of the presence of trout, which also had no influence on their movement patterns or drift activity. Our results suggest that effects of predatory fish on stream invertebrates vary with invertebrate traits such as foraging ecology and predator-avoidance strategies.
\end{abstract}

Additional keywords: behaviour, biological invasions, Ephemeroptera, freshwater ecosystems, Trichoptera.

\section{Introduction}

Invertebrates living in streams where predatory fish are present are often able to detect them through water-borne chemical cues and respond with behavioural changes that lower predation risk, typically by decreasing their activity level (Flecker and Townsend 1994; McIntosh and Townsend 1995; Chivers 1998; Boyero et al. 2008) or drifting mostly at nighttime (Flecker 1992; Huhta et al. 1999; Boyero and Bosch 2002). Although most of the relevant literature deals with mayflies (Flecker 1992; McIntosh and Townsend 1995; McIntosh et al. 1999; Huhta et al. 2000), there is also evidence that some other taxa modify their behaviour in response to predators (e.g. the amphipod Gammarus pulex, Åbjörnsson et al. 2000), whereas some do not (e.g. the caddisfly Allomyia sp., Álvarez and Peckarsky 2005).

Effects of predators on prey behaviour can vary with differences in predator foraging strategies. For example, nymphs of Baetis rhodani drifted mostly at night when exposed to chemical cues from diurnal fish predators, whereas they showed no drift diel periodicity when exposed to cues from nocturnal caddisfly predators (Huhta et al. 1999). We hypothesised that different foraging strategies of prey can also lead to contrasting behavioural responses to a given predator. For example, although grazing mayflies are generally vulnerable to fish predation while they feed on periphyton growing on upper surfaces of stones, detritivorous caddisflies such as limnephilids are unlikely to be detected by predatory fish while foraging on decaying organic matter (Boyero 2011). Moreover, these caddisflies live within a case that they build, using mineral or organic material, providing themselves potential protection against predators (Mackay and Wiggins 1979; Boyero et al. 2006; Stevens et al. 1999).

We predicted that, when exposed to chemical cues from a predatory fish, grazing mayflies would behave in a way to minimise predation risk, whereas caddisflies would show similar behaviours irrespective of whether fish cues were present or absent. We tested this hypothesis by examining several behavioural traits of two mayfly and two caddisfly species, in two reaches of a montane stream in central Spain, namely a reach where brown trout (Salmo trutta) has been recently introduced from further downstream, and an upstream, fishless reach. We specifically hypothesised that mayflies would respond to the presence of fish cues by reducing their movement on the substrate, increasing their entrance into the drift, and drifting mostly at night, whereas caddisflies would not modify their behaviour (time spent within their case when disturbed, and movement patterns afterwards) with or without fish cues.

We further explored the flexibility of mayfly anti-predator behaviour. The absence, in certain stream reaches, of predatory fish that are present further downstream, can enable the evolution of 'naiveté', or lack of capacity to recognise the threat of such predators (Cox and Lima 2006). The subsequent invasion 
of those stream reaches by fish can cause substantial changes in prey populations (Cox and Lima 2006), and some studies have suggested that certain behavioural responses in mayflies can evolve rapidly, such as reduced drift or grazing activity during the day (Flecker 1992; Townsend 2003). We tested the hypothesis that predator-mediated reduced movement and drift rates in mayflies disappear shortly after trout are removed from the stream reach by electrofishing.

\section{Materials and methods}

\section{Study area}

The study was conducted in 2003 at the Pepe Hernando stream, in the Peñalara Natural Park (Sierra de Guadarrama, central Spain, $40850^{\circ} \mathrm{N}, 3857^{\circ} \mathrm{W}$ ), an alpine area composed of several small glacial valleys between 1800 and $2430 \mathrm{~m}$ asl. The area contains hundreds of interconnected ponds and small rivulets, most of which drain into two larger streams, the Peñalara and Pepe Hernando, which eventually join and flow into the Lozoya River (Tajo drainage). The Pepe Hernando is a small, clear mountain stream with alternating pools, riffles, runs and cascades. Pebbles and gravel are the dominant substrate types, and riparian vegetation is scarce, composed of alpine meadows (Nardus stricta) and sparse thickets of Pinus sylvestris.

Brown trout was introduced in upstream reaches of the Pepe Hernando stream from nearby downstream areas several decades ago (Bosch et al. 2006). Those previously fishless reaches were located above a high-gradient section of the stream that had prevented trout colonisation. Brown trout dispersed some $300 \mathrm{~m}$ upstream up to a 1-m-high cascade, establishing a small isolated population (Bosch et al. 2006). Macroinvertebrate assemblages at the Pepe Hernando stream are abundant and species-rich. Among the dominant taxa are baetid and heptageniid mayflies (mainly Baetis sp. and Epeorus sp., respectively; densities of Baetis sp. , 350 T 82 individuals $\mathrm{m}^{-2}$ ) and limnephilid caddisflies (mainly Potamophylax latipennis and Chaetopteryx sp.; densities of P. latipennis, 95 T 5 individuals $\mathrm{m}^{-2}$ ) (Boyero 2003a, 2003b; Boyero et al. 2006; L. Boyero, unpubl. data).

Two stream reaches of similar width $(, 2 \mathrm{~m})$ and depth $(, 50 \mathrm{~cm})(\mathrm{P}-0.5$ in both cases) were used for the study, one upstream and one downstream of the above-mentioned cascade (i.e. a fishless reach and one with introduced brown trout, respectively). Both reaches were separated by , $20 \mathrm{~m}$, so differences in water chemistry were unlikely. The proportion of different habitat types (riffles, pools, runs and cascades) was not significantly different between reaches ( $\left.x^{2} 1 / 44.92, P^{1 / 4} 0.18\right)$. At each reach, we made the observations described below.

\section{Behavioural observations: grazing mayflies}

We observed the rates of movement of Baetis sp. and Epeorus sp. nymphs (hereafter, Baetis and Epeorus) on the substrate, and entrance into the drift, through a $20 \times 20$-cm glass-bottom frame. Observations were made between 7 and 21 July at randomly selected locations in the upstream and downstream reaches, until 40 observations per species and reach were completed. We recorded (1) the total number of individuals within the frame (n), (2) the number of individuals moving on the substrate (m) and (3) the number of individuals entering the drift (i.e. leaving the substrate and entering the water column, d). We then calculated the per capita rates of movement $(\mathrm{m} / \mathrm{n})$ and drift $(\mathrm{d} / \mathrm{n})$. We made five 2-min observations at each location, separated by $30 \mathrm{~s}$, and used the mean values of the five observations.

Once these observations had been completed, we removed the brown trout from the downstream reach by using a backpack electroshocker (DC 200-400 V, , 1 A, Deka 3000, Marsberg, Germany), releasing the individuals further downstream where brown trout occur naturally. Electrofishing has been conducted on successive years, and no brown trout have subsequently been found. One month after trout removal (2 September), we repeated the observations at 32 locations for each species (18 and 14 in the upstream and downstream reaches, respectively). No apparent changes in nymph developmental stages were noted compared with the July observations. Arcsin square root-transformed rates of movement and drift were compared between periods (before and after trout removal), between the upstream and downstream reaches (nested within period to avoid pseudoreplication, Smith 2002) and between species, with three-way ANOVAs followed by post hoc Tukey tests. A sequential Bonferroni correction was applied to the P-values to compensate for the multiple tests.

\section{Behavioural observations: detritivorous caddisflies}

We observed the responses of P. latipennis and Chaetopteryx sp. larvae (hereafter, Potamophylax and Chaetopteryx) to a potential predation threat, before trout removal (14-21 July). Observations were made using the glass-bottom quadrat and a video camera. We first located an individual that was moving on the stream substrate, and video-recorded it for $3 \mathrm{~min}$. We then disturbed it by gently touching it with a stick (all individuals immediately responded to this potential predation threat by withdrawing into their case), quantified the elapsed time until the animal re-emerged from the case and started moving, and video-recorded it for a further $3 \mathrm{~min}$. This procedure was repeated for 20 larvae in each of the study reaches. Animals were preserved in $70 \%$ ethanol and identified.

Because $85 \%$ of the larvae observed in the upstream reach were Potamophylax (15\% Chaetopteryx), whereas $85 \%$ of those observed in the downstream reach were Chaetopteryx (5\% Potamophylax and $10 \%$ an unidentified species), we made another set of observations in which 30 individuals of each species were collected and placed in the stream within a $20 \times 20$-cm plastic container, the bottom of which had been filled with substrate. Half the animals were placed in the upstream reach and the other half in the downstream reach. Larvae were left to be acclimated within the containers until they started moving. We then repeated the above procedure (i.e. video-recorded for $3 \mathrm{~min}$, disturbed, and video-recorded for another $3 \mathrm{~min}$ once larvae started moving). The recordings were later examined and the following variables quantified: the time (in seconds) elapsed until the animal re-emerged from its case and started moving after the disturbance; the velocity of movement (distance covered per second, the distance unit being the animal body length) before and after the disturbance; and the number of turns in their movement (i.e. changes in direction) before and after the disturbance. 
Table 1. Results of ANOVAs exploring variation in mayfly (Baetis $\mathrm{sp}$. and Epeorus sp.) movement on the substrate and entrance into the drift, in different periods (before $v$. after trout removal) and reaches (upstream v. downstream; nested within each period)

Asterisks indicate significant results after applying a sequential Bonferroni correction

\begin{tabular}{lrrc}
\hline Source of variation & d.f. & $\mathrm{F}$ & $\mathrm{P}$ \\
\hline Mayfly movement rates & 1 & 0.02 & 0.913 \\
$\quad$ Period & 2 & 30.15 &, $0.0001^{*}$ \\
Reach (Period) & 1 & 3.12 & 0.079 \\
Species & 1 & 0.01 & 0.945 \\
Period $\times$ Species & 2 & 4.83 & $0.009^{*}$ \\
Reach (Period) $\times$ Species & 216 & & \\
$\quad$ Error & & & \\
Mayfly drift rates & 1 & 0.26 & 0.663 \\
Period & 2 & 10.11 &, $0.0001^{*}$ \\
Reach (Period) & 1 & 4.59 & 0.033 \\
Species & 1 & 0.03 & 0.887 \\
Period $\times$ Species & 2 & 0.85 & 0.428 \\
Reach (Period) $\times$ Species & 216 & & \\
Error & & & \\
\hline
\end{tabular}

Observations made on the stream substrate and in the containers were analysed separately. For those on the substrate, we compared the $\log _{\mathrm{e}}$-transformed retreat time between species with one-way ANOVA, and the $\log _{\mathrm{e}}$-transformed velocity of movement and number of turns between periods (before and after the disturbance) and between species with repeatedmeasures ANOVA (period being a within-subject factor). A sequential Bonferroni correction was applied to P-values between retreat time, velocity of movement and number of turns. For observations in containers, we compared the $\log _{\mathrm{e}}$-transformed retreat time between species and between the upstream and downstream reaches with two-way ANOVA, and the $\log _{\mathrm{e}}{ }^{-}$ transformed velocity of movement and number of turns between periods, species and reaches with repeated-measures ANOVA (period being a within-subject factor). We were particularly interested in the interactions reach $\times$ period and species $\times$ reach $\times$ period, which would indicate an effect of fish presence on disturbance reaction. As before, sequential Bonferroni corrections were made to P-values.

Because Potamophylax and Chaetopteryx were dominant in the upstream (fishless) and downstream (fish) reaches, respectively, we tested the hypothesis that case resistance of
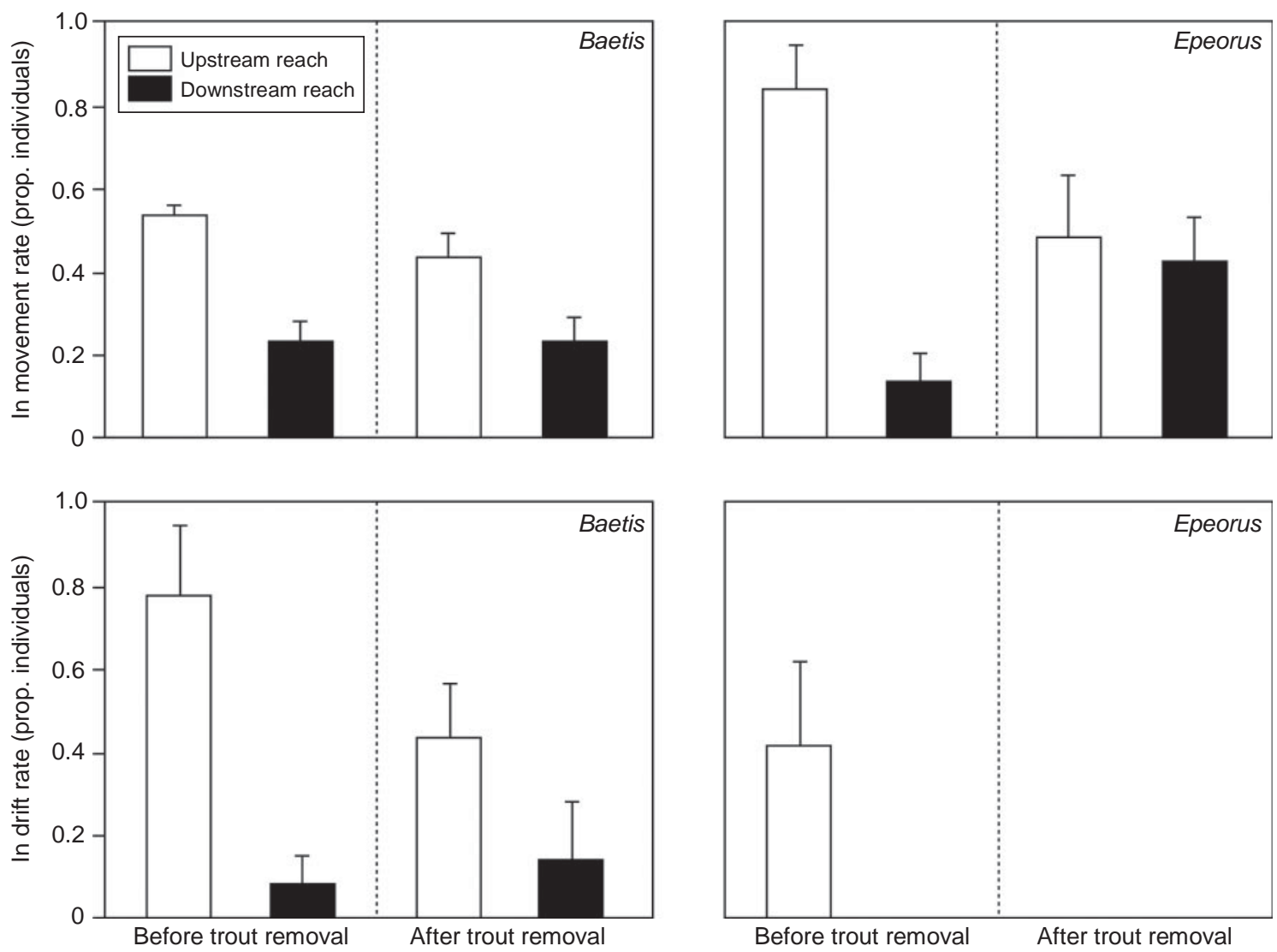

Fig. 1. Mean T s.e. rates of movement on the substrate and entrance into the drift of Baetis sp. and Epeorus sp. in the two study-stream reaches (upstream: fishless reach; downstream: reach where brown trout has been introduced), before and after trout had been removed from the downstream reach by electrofishing. 
Table 2. Results of ANOVAs exploring variation in the time caddisflies (Potamophylax latipennis and Chaetopteryx sp.) remain within their case when disturbed, and in their velocity of movement and number of turns before $v$. after the disturbance (observations made on the stream substrate)

Asterisks indicate significant results after applying a sequential Bonferroni correction

\begin{tabular}{lrcc}
\hline Source of variation & d.f. & F & P \\
\hline $\begin{array}{l}\text { Caddisfly retreat time } \\
\quad \text { Species }\end{array}$ & 1 & 10.89 & $0.002^{*}$ \\
$\quad$ Error & 38 & & \\
$\quad \begin{array}{l}\text { Caddisfly velocity } \\
\quad \text { Species }\end{array}$ & 1 & 59.07 &, $0.0001^{*}$ \\
$\quad$ Error & 38 & & \\
$\quad$ Period & 1 & 34.50 &, $0.0001^{*}$ \\
$\quad$ Species $\times$ Period & 1 & 26.32 &, $0.0001^{*}$ \\
$\quad$ Error & 38 & & \\
Caddisfly turns & & & \\
$\quad$ Species & 1 & 50.18 &, $0.0001^{*}$ \\
$\quad$ Error & 38 & &, $0.0001^{*}$ \\
$\quad$ Period & 1 & 20.35 &, $0.0001^{*}$ \\
$\quad$ Species $\times$ Period & 1 & 15.70 & \\
$\quad$ Error & 38 & & \\
\hline
\end{tabular}

Chaetopteryx was higher than that of Potamophylax, the latter being more vulnerable to fish predation (and thus scarce at the downstream reach). To do this, we estimated the resistance of their cases to crushing, using two plastic-graduated cylinders that fitted into each other. The case was placed into the larger cylinder, whereas the smaller cylinder was gently placed on top of the case and slowly filled with water until the case was crushed. We followed this procedure with the empty cases of the 60 individuals used in the observations within containers. We compared the $\log _{\mathrm{e}}$-transformed water volume needed to crush the cases of both caddisfly species, by using one-way ANOVA.

\section{Drift}

Invertebrate drift was quantified at the upstream and downstream reaches before trout removal (2-10 June). Twenty samples were collected at random locations within each reach, half of them at daytime (1800-2030 hours) and the other half at nighttime (2130-2230 hours), with a 0.5-mm-mesh drift net with a 15-cm-diameter circular mouth. Current velocity was measured with a Marsh-McBirney 201 current meter (accurate to T0.01 $\mathrm{cm} \mathrm{s}^{-1}$ ) at each sampling point, and sampling time was established on the basis of current velocity for a total water volume sampled of , $65 \mathrm{~L}$ in all cases. Samples were preserved in $4 \%$ formalin and examined in the laboratory, where all invertebrates were counted and identified. We compared the $\log _{\mathrm{e}}$-transformed densities of Baetis, Epeorus and Potamophylax (Chaetopteryx was not found in the samples) between the upstream and downstream reaches, and between daytime and nighttime, with three-way ANOVA followed by post hoc Tukey tests.
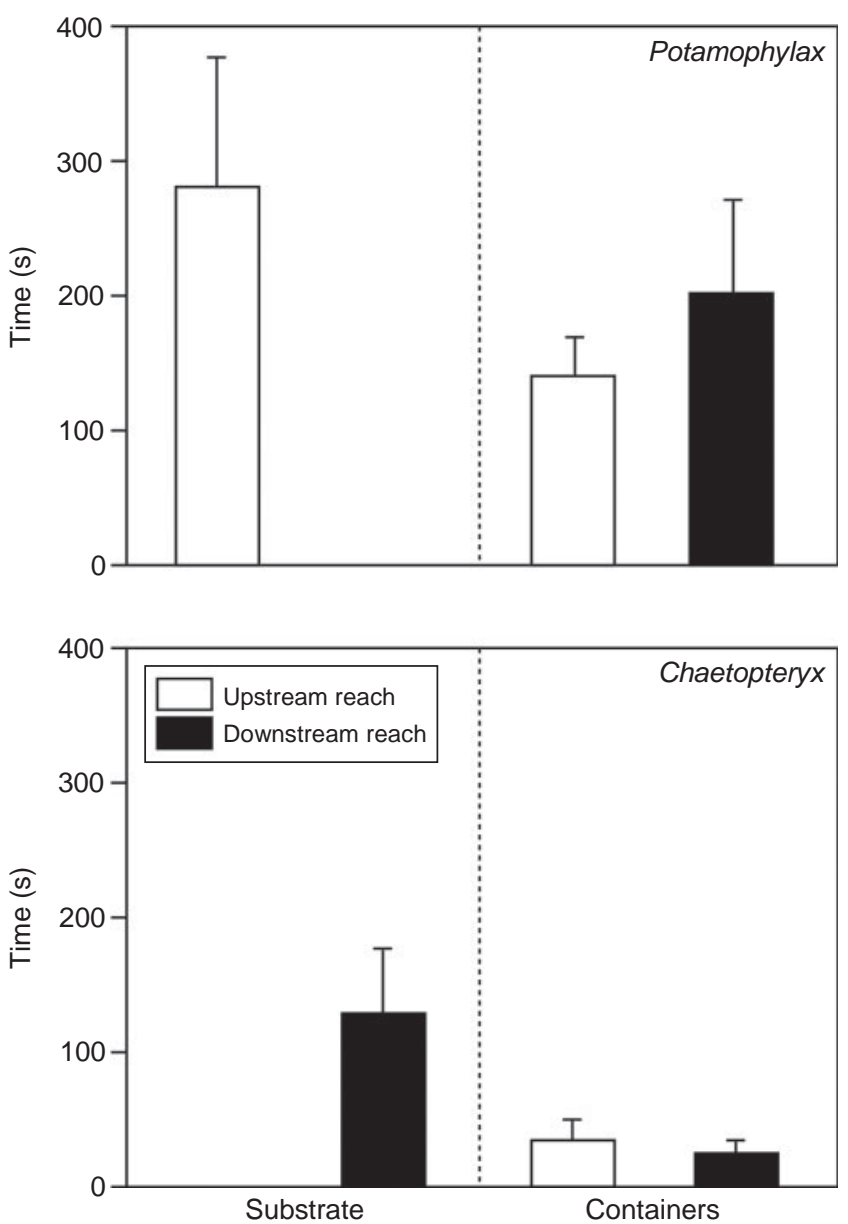

Fig. 2. Mean T s.e. time limnephilid caddisflies (Potamophylax latipennis and Chaetopteryx sp.) were withdrawn within their case after a potential predation threat (being touched with a stick). Observations were made on the stream substrate (with Potamophylax sp. present only in the upstream reach and Chaetopteryx sp. in the downstream reach) and within containers (with both species previously collected and placed in both reaches).

\section{Results}

\section{Behavioural observations: grazing mayflies}

Rates of mayfly movement and entrance into the drift did not differ between periods, but varied between reaches (Table 1 ). However, differences between reaches were significant only before trout removal (movement and drift rates being higher in the fishless reach, Fig. 1). Movement rates were higher in Epeorus than in Baetis in the fishless reach (significant reach $x$ species interaction). Epeorus entered the drift only in the fishless reach and only before trout removal (Fig. 1); however, differences in drift between species were non-significant (Table 1).

\section{Behavioural observations: detritivorous caddisflies}

In observations on the stream substrate, Potamophylax stayed in their cases longer after disturbance than did Chaetopteryx (Table 2, Fig. 2). Velocity of movement was higher after the 

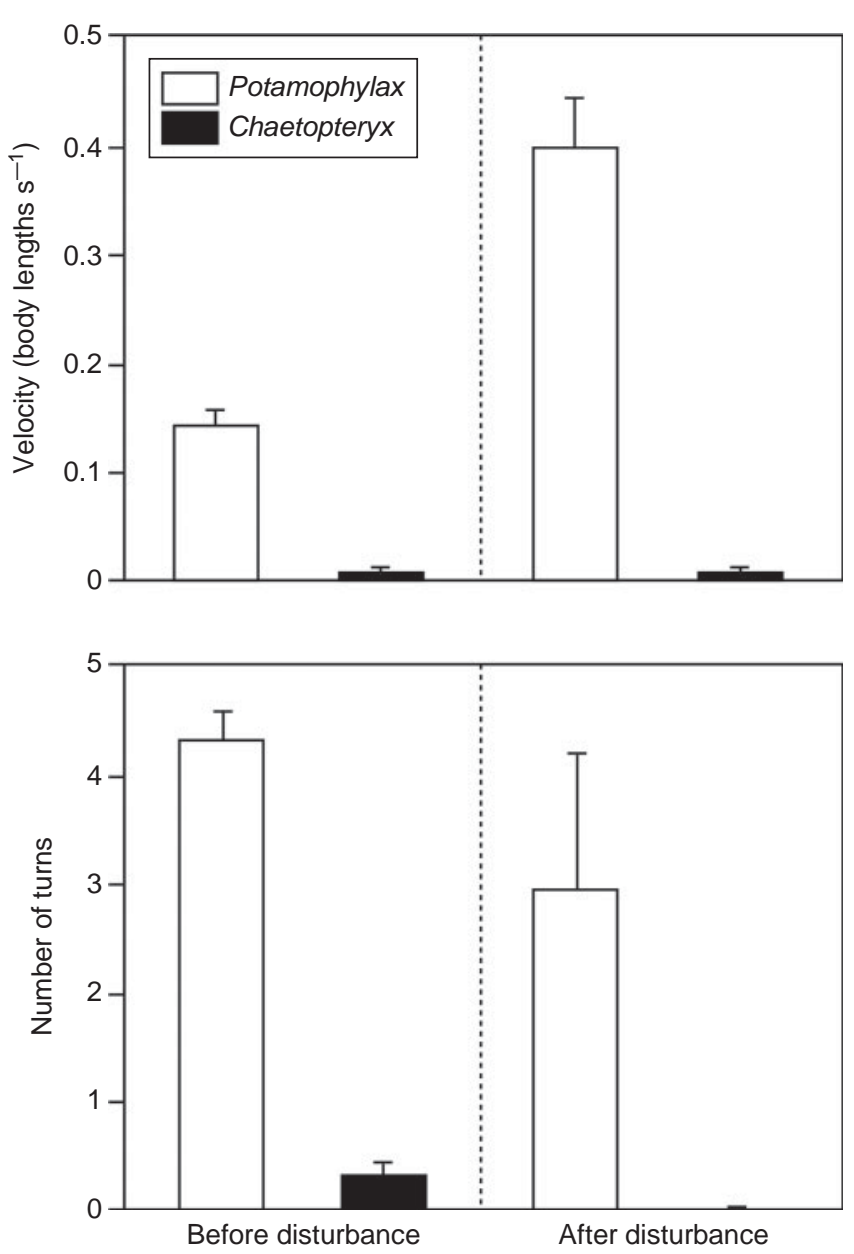

Fig. 3. Mean T s.e. velocity of movement and number of turns of limnephilid caddisflies (Potamophylax latipennis and Chaetopteryx sp.) before and after the potential predation threat (observations made on the stream substrate).

disturbance, but only for Potamophylax, and the number of turns was higher before the disturbance, again only for this species (significant period $\times$ species interaction in both cases) (Table 2 , Fig. 3). In observations within containers, retreat time was also higher for Potamophylax and did not differ between the upstream and downstream reaches (Table 3, Fig. 2), as predicted. Velocity of movement and number of turns were both higher for Potamophylax, and were affected by the disturbance for this species (significant period $\times$ species interaction in both cases); however, they did not differ between reaches (Table 3), as predicted; the velocity increased and the number of turns decreased after the disturbance (Fig. 4). Case strength of Chaetopteryx was higher than that of Potamophylax $\left(\mathrm{F}_{1,58} 1 / 423.2, \mathrm{P}, 0.0001\right)$.

Drift

Drift densities were higher for Baetis, and higher in the upstream reach for this species, but not for the others (significant species $\times$ reach interaction; Table 4 , Fig. 5). As we predicted, drift was higher at nighttime, although only for Baetis (significant species $\times$ time interaction; Table 4, Fig. 5).
Table 3. Results of ANOVAs exploring variation in the time caddisflies (Potamophylax latipennis and Chaetopteryx $\mathrm{sp}$.) remain within their case when disturbed, and in their velocity of movement and number of turns before v. after the disturbance and in the upstream v. downstream reaches (observations made within containers) Asterisks indicate significant results after applying a sequential Bonferroni correction

\begin{tabular}{|c|c|c|c|}
\hline Source of variation & d.f. & $\mathrm{F}$ & $\mathrm{P}$ \\
\hline \multicolumn{4}{|l|}{ Caddisfly retreat time } \\
\hline Species & 1 & 34.52 &, $0.0001 *$ \\
\hline Reach & 1 & 0.32 & 0.576 \\
\hline Species $\times$ Reach & 1 & 0.39 & 0.535 \\
\hline Error & 56 & & \\
\hline \multicolumn{4}{|l|}{ Caddisfly velocity } \\
\hline Species & 1 & 74.41 &, $0.0001 *$ \\
\hline Reach & 1 & 5.51 & 0.022 \\
\hline Species $\times$ Reach & 1 & 5.69 & 0.020 \\
\hline Error & 56 & & \\
\hline Period & 1 & 43.98 &, $0.0001^{*}$ \\
\hline Species $\times$ Period & 1 & 45.78 & , 0.0001* \\
\hline Reach $\times$ Period & 1 & 2.67 & 0.108 \\
\hline Species $\times$ Reach $\times$ Period & 1 & 1.69 & 0.199 \\
\hline Error & 56 & & \\
\hline \multicolumn{4}{|l|}{ Caddisfly turns } \\
\hline Species & 1 & 20.73 & , $0.0001 *$ \\
\hline Reach & 1 & 1.26 & 0.266 \\
\hline Species $\times$ Reach & 1 & 0.08 & 0.774 \\
\hline Error & 56 & & \\
\hline Period & 1 & 21.75 &, $0.0001^{*}$ \\
\hline Species $\times$ Period & 1 & 25.36 & , 0.0001* \\
\hline Reach $\times$ Period & 1 & 0.05 & 0.823 \\
\hline Species $\times$ Reach $\times$ Period & 1 & 0.36 & 0.553 \\
\hline Error & 56 & & \\
\hline
\end{tabular}

\section{Discussion}

\section{Mayfly responses to fish chemical cues}

The study findings supported our hypothesis that behavioural responses of grazing mayflies to the presence of an introduced predatory fish are stronger than those of detritivorous cased caddisflies. Individuals of Baetis and Epeorus reduced their rates of movement on the substrate, as well as their rates of entrance into the drift, when brown trout were present. Moreover, reduced movement and drift rates disappeared shortly after brown trout had been removed, as we hypothesised. These observations indicate that behavioural responses of grazing mayflies to introduced brown trout are strong and highly flexible, matching our predictions and findings from other studies with Baetis and other grazing mayflies (Flecker 1992; Huhta et al. 2000; Townsend 2003). The marked drift diel periodicity of Baetis when trout was present could be a result of either a behavioural response, consumption of drifting individuals by trout, or both.

\section{Caddisfly responses to fish chemical cues}

In contrast, limnephilid caddisflies responded to the potential predation threat (being touched with a stick) by retreating into their case, regardless of the presence or absence of brown-trout 

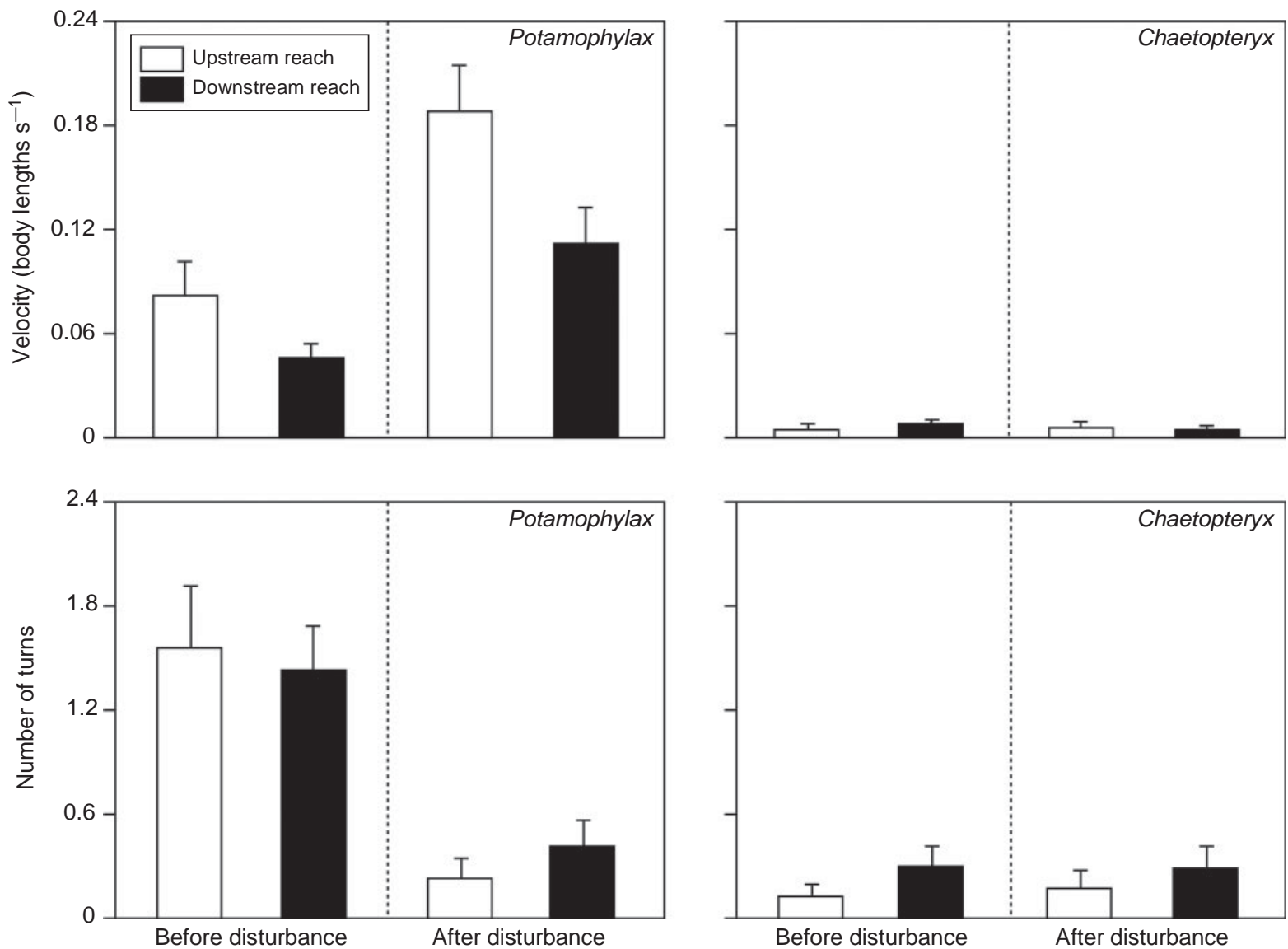

Fig. 4. Mean T s.e. velocity of movement and number of turns of limnephilid caddisflies (Potamophylax latipennis and Chaetopteryx sp.) before and after the potential predation threat (observations made within containers).

Table 4. Results of ANOVAs exploring variation in drift densities of mayflies (Baetis sp. and Epeorus sp.) and caddisflies (Potamophylax latipennis; Chaetopteryx sp. was not found in drift samples) in daytime $v$. nighttime and in the upstream v. downstream reaches

\begin{tabular}{lrrc}
\hline Source of variation & d.f. & F & P \\
\hline Species & 2 & 121.51 &, 0.0001 \\
Reach & 1 & 29.77 &, 0.0001 \\
Species $\times$ Reach & 2 & 23.70 &, 0.0001 \\
Time & 1 & 17.82 &, 0.0001 \\
Species $\times$ Time & 2 & 17.67 &, 0.0001 \\
Reach $\times$ Time & 1 & 5.34 & 0.023 \\
Species $\times$ Reach $\times$ Time & 2 & 2.66 & 0.074 \\
Error & 108 & & \\
\hline
\end{tabular}

chemical cues, again supporting our hypothesis. The time spent within the case was similar on both occasions and, when the caddisflies re-emerged, their movement patterns were the same. We know that some limnephilids, such as Potamophylax, are able to detect brown-trout chemical cues; when uncased individuals were offered mineral and organic cases in the presence of trout cues, they selected tougher (mineral) cases more often than controls not exposed to such cues (Boyero et al. 2006). This suggests that, in the present study, cased individuals detected fish cues but did not modify their behaviour.

A potential explanation for the lack of response is that the case offers them some protection (e.g. smaller fish might be deterred from eating cased larvae). This is supported by the fact that Chaetopteryx did not modify their movement patterns after being disturbed, whereas Potamophylax, with a softer case, moved more rapidly and showed a more linear trajectory after the disturbance. Furthermore, Chaetopteryx was more abundant than Potamophylax in the downstream reach, possibly as a result of higher predation from brown trout on Potamophylax. Other factors may also be responsible for this pattern, such as differences in the physical habitat or community composition (although densities of predatory invertebrates did not differ between reaches, Boyero et al. 2006). Furthermore, although caddisfly cases can have diverse functions (Limm and Power 2011), their protective role has been widely acknowledged (Otto and Svensson 1980; Johansson 1991; Nislow and Molles 1993; Boyero et al. 2006; Stevens et al. 1999).

The spatial segregation of both caddisfly species forced us to collect all Potamophylax larvae (to be used in the container observations) in the upstream reach, and all Chaetopteryx in the downstream reach. Although this may have confounded the results, we believe this is unlikely, given than Potamophylax 

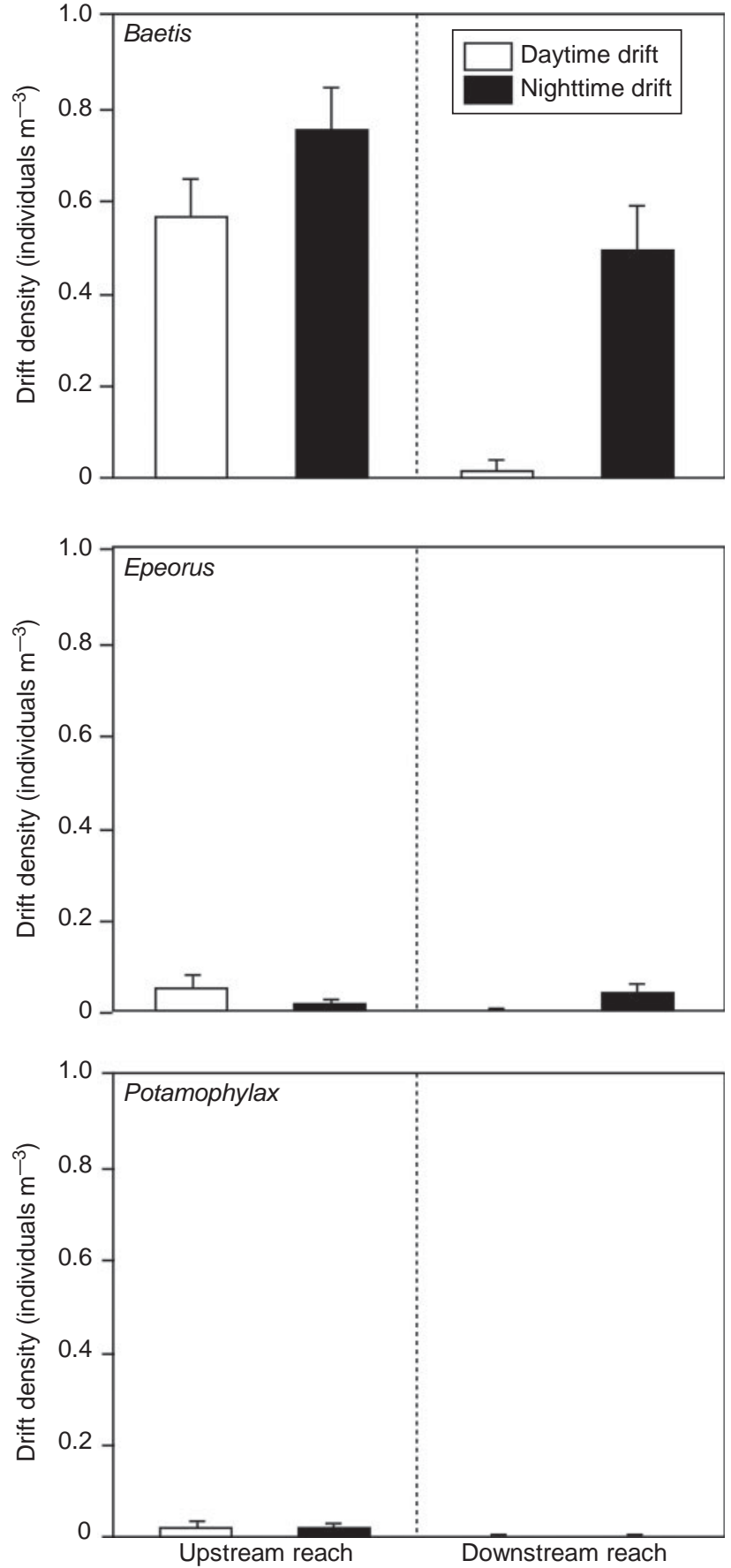

Fig. 5. Mean T s.e. drift densities (in number of individuals per $\mathrm{m}^{3}$ of filtered water) of Baetis sp., Epeorus sp. and Potamophylax latipennis at daytime (1800-2030 hours) and nighttime (2130-2230 hours) in the two study-stream reaches.

larvae collected in the fishless reach are able to recognise brown-trout chemical cues (Boyero et al. 2006).

\section{Conclusion}

The different responses of grazing mayflies and detritivorous caddisflies to the presence of trout are likely to be related to their contrasting foraging ecology. Grazing mayflies are exposed to visual predators while feeding on periphyton on the upper faces of stones, and thus generally avoid predation by modifying their behaviour (Tikkanen et al. 1994; McIntosh and Townsend 1995; Peckarsky 1996). In contrast, detritivorous (cased) caddisflies forage among decaying organic matter and are less visible, and more protected from by their case (see references in the previous paragraph).

However, the responses may also be due in part to taxonomic differences between mayflies and caddisflies. To separate both sources of variation, future studies should compare grazer and detritivore species within each of the orders. It would also be worth exploring potential differences in top-down effects on autotrophic v. heterotrophic resources, mediated by differential responses of grazers and detritivores to predators, to assess the potential consequences of such behavioural traits at the ecosystem level.

\section{Acknowledgements}

We thank three anonymous reviewers and the Associate Editor for their valuable comments. The Spanish Ministry for Science and Innovation funded the study (project CGL2006-05075) and the Comunidad de Madrid extended permits for field work. L. B. is currently supported by the Ramón y Cajal program from the Spanish Ministry for Science and Innovation.

\section{References}

Åbjörnsson, K. J., Dahl, J., Nyström, P., and Brönmark, C. (2000). Influence of predator and dietary chemical cues on the behaviour and shredding efficiency of Gammarus pulex. Aquatic Ecology 34, 379-387. doi:10.1023/A:1011442331229

Álvarez, M., and Peckarsky, B. L. (2005). How do grazers affect periphyton heterogeneity in streams? Oecologia 142, 576-587. doi:10.1007/ S00442-004-1759-0

Bosch, J., Rincón, P. A., Boyero, L., and Martínez-Solano, I. (2006). Effects of introduced salmonids on a montane population of Iberian frogs. Conservation Biology 20, 180-189. doi:10.1111/J.1523-1739.2005. 00296.X

Boyero, L. (2003a). Multiscale patterns of spatial variation of stream macroinvertebrate communities. Ecological Research 18, 365-379. doi:10.1046/J.1440-1703.2003.00562.X

Boyero, L. (2003b). The effect of substrate texture on patch colonization by stream macroinvertebrates. Annales de Limnologie - International Journal of Limnology 39, 211-218. doi:10.1051/LIMN/2003017

Boyero, L. (2011). Expression of a behaviourally mediated morphology in response to different predators. Ecological Research. doi:10.1007/ S11284-011-0856-X

Boyero, L., and Bosch, J. (2002). Spatial and temporal variation of macroinvertebrate drift in two neotropical streams. Biotropica 34, 567-574.

Boyero, L., Rincón, P. A., and Bosch, J. (2006). Case selection by a limnephilid caddisfly [Potamophylax latipennis, Curtis.] in response to different predators. Behavioral Ecology and Sociobiology 59, 364-372. doi:10.1007/S00265-005-0059-Y

Boyero, L., Rincón, P. A., and Pearson, R. G. (2008). Effects of a predatory fish on a tropical detritus-based food web. Ecological Research 23, 649-655. doi:10.1007/S11284-007-0424-6

Chivers, D. P. (1998). Chemical alarm signalling in aquatic predator-prey systems: a review and prospectus. Ecoscience 5, 338-352.

Cox, J. G., and Lima, S. L. (2006). Naiveté and an aquatic-terrestrial dichotomy in the effects of introduced predators. Trends in Ecology \& Evolution 21, 674-680. doi:10.1016/J.TREE.2006.07.011

Flecker, A. S. (1992). Fish predation and the evolution of invertebrate drift periodicity: evidence from Neotropical streams. Ecology 73, 438-448. doi:10.2307/1940751 
Flecker, A. S., and Townsend, C. R. (1994). Community-wide consequences of trout introduction in New Zealand streams. Ecological Applications 4, 798-807. doi:10.2307/1942009

Huhta, A., Muotka, T., Juntunen, A., and Yrjonen, M. (1999). Behavioural interactions in stream food webs: the case of drift-feeding fish, predatory invertebrates and grazing mayflies. Journal of Animal Ecology 68, 917-927. doi:10.1046/J.1365-2656.1999.00339.X

Huhta, A., Muotka, T., and Tikkanen, P. (2000). Nocturnal drift of mayfly nymphs as a post-contact antipredator mechanism. Freshwater Biology 45, 33-42. doi:10.1046/J.1365-2427.2000.00615.X

Johansson, A. (1991). Caddis larvae cases (Trichoptera, Limnephilidae) as anti-predatory devices against brown trout and sculpin. Hydrobiologia 211, 185-194. doi:10.1007/BF00008534

Limm, M. P., and Power, M. E. (2011). The caddisfly Dicosmoecus gilvipes: making a case for a functional role. Journal of the North American Benthological Society 30, 485-492. doi:10.1899/10-028.1

Mackay, R. J., and Wiggins, G. B. (1979). Ecological diversity in Trichoptera. Annual Review of Entomology 24, 185-208. doi:10.1146/ ANNUREV.EN.24.010179.001153

McIntosh, A. R., and Townsend, C. R. (1995). Impacts of an introduced predatory fish on mayfly grazing in New Zealand streams. Limnology and Oceanography 40, 1508-1512. doi:10.4319/LO.1995.40.8.1508

McIntosh, A. R., Peckarsky, B. L., and Taylor, B. W. (1999). Rapid sizespecific changes in the drift of Baetis bicaudatus (Ephemeroptera) caused by alterations in fish odour concentration. Oecologia 118, 256-264. doi:10.1007/S004420050726
Nislow, K. H., and Molles, M. C., Jr (1993). The influence of larval case design on vulnerability of Limnephilus frijole (Trichoptera) to predation. Freshwater Biology 29, 411-417. doi:10.1111/J.1365-2427.1993. TB00775.X

Otto, C., and Svensson, B. S. (1980). The significance of case material selection for the survival of caddis larvae. Journal of Animal Ecology 49, 855-865. doi:10.2307/4231

Peckarsky, B. L. (1996). Alternative predator avoidance syndromes of stream-dwelling mayfly larvae. Ecology 77, 1888-1905. doi:10.2307/ 2265792

Smith, E. P. (2002). BACI design. In 'Encyclopedia of Environmetrics. Vol. 1'. (Eds A. H. El-Shaarawi and W. W. Piegorsch.) pp. 141-148. (John Wiley \& Sons: Chichester, UK.)

Stevens, D. J., Hansell, M. H., Freel, J. A., and Monagahan, P. (1999). Developmental trade-offs in caddis flies: increased investment in larval defence alters adult resource allocation. Proceedings. Biological Sciences B. Biological Sciences 266, 1049-1054. doi:10.1098/RSPB. 1999.0742

Tikkanen, P., Muotka, T., and Huhta, A. (1994). Predator detection and avoidance by lotic mayfly nymphs of different size. Oecologia 99 , 252-259. doi:10.1007/BF00627737

Townsend, C. R. (2003). Individual, population, community, and ecosystem consequences of a fish invader in New Zealand streams. Conservation Biology 17, 38-47. doi:10.1046/J.1523-1739.2003.02017.X 